\title{
ß3-Adrenoceptor Mediates Metabolic Protein Remodeling in a Rabbit Model of Tachypacing-Induced Atrial Fibrillation
}

\author{
Yixi Liu ${ }^{a}$ Jianqiang Geng ${ }^{a}$ Yutan Liu ${ }^{a}$ Yue Lia Jingxia Shen ${ }^{b} \quad$ Xingping Xiao ${ }^{a}$ \\ Li Sheng $^{a}$ Baofeng Yang ${ }^{c}$ Cheping Cheng ${ }^{d}$ Weimin Li ${ }^{a}$
}

aDepartment of Cardiology, The First Affiliated Hospital, Harbin Medical University, Harbin, bUltrasonic cardiogram room, Department of Cardiology, The First Affiliated Hospital, Harbin Medical University, Harbin, 'Department of Pharmacology, Harbin Medical University and Bio-Pharmaceutical Key Laboratory of Heilongjiang Province and State, Harbin, China; ${ }^{d}$ Section of Cardiology, Wake Forest University School of Medicine, Winston-Salem, North Carolina, USA

\section{Key Words}

Metabolic remodeling • $\beta 3$-adrenoceptor • Atrial fibrillation • PPAR $\alpha / P G C-1 \alpha$

\begin{abstract}
Background: The beta 3-adrenoceptor ( $\beta 3-A R)$ is closely associated with energy metabolism. This study aimed to explore the role of $\beta 3-A R$ in energy remodeling in a rabbit model of pacing-induced atrial fibrillation (AF). Methods: Rabbits with a sham-operation or pacinginduced AF were used for this study, and the latter group was further divided into three subgroups: 1) the pacing group, 2) the $\beta 3-A R$ agonist (BRL37344)-treated group, and 3) the $\beta 3-A R$ antagonist (SR59230A)-treated group. Atrial electrogram morphology and surface ECG were used to monitor the induction of AF and atrial effective refractory period (AERP). RTPCR and western blot (WB) were used to show alterations in $\beta 3-A R$ and metabolic-related protein. Results: RT-PCR and WB results showed that $\beta 3-A R$ was significantly upregulated in the pacing group, and that it corresponded with high AF inducibility and significantly decreased $A E R P_{200}$ and ATP production in this group. Inhibition of $\beta 3-A R$ decreased the $A F$ induction rate, reversed $A E R P_{200}$ reduction, and restored ATP levels in the AF rabbits. Further activation of $\beta 3-A R$ using agonist BRL37344 exacerbated AF-induced metabolic disruption. Periodic acid Schiff (PAS) and Oil Red O staining showed $\beta 3$-AR-dependent glycogen and lipid droplet accumulation in cardiac myocytes with AF. Glucose transporter-4 (GLUT-4) and CD36, key transporters of glucose and fatty acids, were downregulated in the pacing group. Expression of carnitine-palmitoyltransferase I (CPT-1), a key regulator in fatty acid metabolism, was also significantly downregulated in the pacing group. Reduced glucose transportation and fatty acid oxidation could be restored by inhibition of $\beta 3-A R$. Furthermore, key regulators of metabolism, peroxisome proliferator-activated receptor- $\alpha$ (PPAR $\alpha)$ and PPAR co-activator (PGC-1 $\alpha)$ can be regulated by pharmacological intervention


of the $\beta 3-A R$. Conclusions: $\beta 3-A R$ is involved in metabolic protein remodeling in AF. PPAR $\alpha$ / PGC- $1 \alpha$ signaling pathway might be the relevant down-stream molecular machinery in response to AF-induced activation of $\beta 3-A R$. $\beta 3-A R$ might be a novel target in AF treatment.

Copyright (C) 2013 S. Karger AG, Basel

\section{Introduction}

Atrial fibrillation (AF), the most common cardiac arrhythmia, is associated with morbidity and mortality in heart failure. Studies of animal models with electrically induced AF, and clinical experience of paroxysmal AF in humans both suggest that AF is a self-perpetuating arrhythmia [1, 2]. AF-induced electrical, contractile, and structural remodeling contribute to persistent $\mathrm{AF}$ [3]. Recently, a study using combined metabolomic and proteomic analysis reported changes in metabolic proteins in persistent $\mathrm{AF}$ in human patients [4]. Diabetic patients also showed higher susceptibility to AF [5]. This suggests that metabolic remodeling and dysfunction might also contribute to AF persistence, whereas the molecular mechanism underlying the impact of cardiac metabolic remodeling on AF persistence remains unclear. Moreover, metabolic activity is known to be closely linked to ion channel functions whose alternation is the basis of electric remodeling in arrhythmia, indicating that metabolic remodeling might be associated with arrhythmia through effects on ion homeostasis [6]. A better understanding of the molecular mechanisms underlying cardiac metabolic remodeling in AF may provide valuable information that could identify potential new targets for pharmacological interventions for the treatment of AF.

The activation of $\beta$-adrenoceptors ( $\beta$-ARs) has been reported to participate in the regulation of cardiac functions [7]. Thus far, at least three subtypes, $\beta 1-, \beta 2-$, and $\beta 3$-ARs, have been identified in the human atrium. The $\beta 3$-AR differs from the other two $\beta$-ARs in its molecular structure and pharmacological functions [7]. While $\beta 1$ - and $\beta 2$-AR2 stimulation leads to increased heart contractility, $\beta 3$-AR stimulation mediates attenuation of cardiac contractility [8]. Although the expression and function of $\beta 3$-ARs in the human heart were identified decades ago, the precise mechanism of $\beta 3$-AR in cardiac regulation remains unclear. It has been classically thought that $\beta 3$-AR mediates metabolic processes (e.g., lipolysis) in adipocytes [9]. A recent report from Yu et al. showed that activation of $\beta 3$ AR promoted atrial electrical remodeling, possibly by altering the calcium and potassium current, in rapidly paced atrial myocytes [10]. Additionally, Sheng et al. also found that in the canine model of pacing-induced AF, upregulation of the $\beta 3$-AR contributed to oxidative stress, and exacerbated atrial structural remodeling [11]. These studies indicated a close link between $\beta 3-\mathrm{AR}$ and $\mathrm{AF}$, while it has not been reported whether $\beta 3-\mathrm{AR}$ affects energy metabolic remodeling in the initiation and persistence of $\mathrm{AF}$, and the possible signaling pathway involved after the activation of $\beta 3$-AR remains unknown.

Cardiac function of the human heart and the rabbit heart is similar, and $\beta 3-\mathrm{AR}$ is expressed in rabbit ventricular cardiomyocytes [12]. Activation of $\beta 3$-AR resulted in decreased rabbit cardiomyocyte contractility and a shortened action potential duration [12]. In this study, we used a rabbit model of pacing-induced AF to investigate the role of $\beta 3-\mathrm{AR}$ in metabolic remodeling. Cardiac metabolic remodeling has been reported to be associated with an increased dependence on glucose, rather than fatty acids [13]. These substrates are transported into cardiomyocytes by glucose transporter-4 (GLUT-4) and the fatty acid transporter CD36 [14]. Carnitine-palmitoyltransferase I (CPT-1) is a rate-limiting enzyme in fatty acid metabolism [15], and downregulation of CPT-1 is associated with decreased fatty acid metabolism resulting in increased lipid droplet aggregation and plasma fatty acid levels. Changes in the activity and kinetic properties of these proteins might cause altered oxidation of fatty acids and glucose $[16,17]$. Therefore, to determine whether activation of $\beta 3$-AR mediated disrupted energy metabolism, we compared the expression levels of CD36, CPT-1, and GLUT-4 between groups. Stimulation of $\beta 3$-AR could mediate fatty acid oxidation and reduction through the activation of extracellular mitogen-activated protein 
kinase (MAPK) and peroxisome proliferator-activated receptor- $\alpha$ (PPAR $\alpha$ ) pathways, and this process has been shown to be associated with enhanced metabolic remodeling in heart failure [18]. In this respect, we further investigated whether the PPAR $\alpha / P G C-1 \alpha$ signaling pathway is involved in the $\beta 3$-AR-mediated effect in metabolic remodeling.

\section{Materials and Methods}

\section{Rabbit model of AF and experimental groups}

Animal handling was in agreement with the Guide for the Care and Use of Laboratory Animals (NIH Publication No. 85-23), and the procedures were approved by the Animal Experimentation Ethics Committee of Harbin Medical University.

The AF animal model was previously established by Yu et al. [10]. Briefly, New Zealand white rabbits (2.0 - $2.5 \mathrm{~kg}$ ) were anesthetized with ketamine (35 mg/kg; Sigma Aldrich, St. Louis, MO, USA) and xylazine ( $5 \mathrm{mg} / \mathrm{kg}$, i.m., Sigma Aldrich). Additional doses (ketamine, $15 \mathrm{mg} / \mathrm{kg}$; xylazine, $2 \mathrm{mg} / \mathrm{kg}$ ) were given as necessary to maintain appropriate anesthesia. The adequacy of anesthesia was confirmed by observing a complete loss of corneal reflexes and by the absence of any reaction to incision. Vital signs were monitored for all procedures. A sterile thoracotomy was performed under mechanical ventilation after intubation. A bipolar electrode was placed and sutured into the right atrium, and was then connected with a programmable pacemaker (Fudan University, Shanghai, China). After 7 days of recovery, rabbits were divided into two groups: 1$)$ the control group $(n=8)$ that had sinus rhythm in which the pacemaker remained off, and 2) the pacing group ( $\mathrm{P} 7, \mathrm{n}=24)$ with the pacemaker turned on and maintained for 1 week at 600 beats per minute (bpm). A surface ECG was recorded once a day to monitor the pacing rate.

\section{Experimental protocol}

When pacing was started, the pacing group was further divided into three groups: 1) the random group ( $n=8$ ) in which animals received no treatment, 2) the BRL group in which animals were treated with a $\beta 3$-AR agonist (BRL37344), and 3) the SR group in which animals were treated with a $\beta 3$-AR antagonist (SR59230A). All experiments were carried out in the presence of 10- $\mu \mathrm{M}$ nadolol (an antagonist for $\beta 1$ - and B2-ARs) 30 min before antagonist or agonist infusion. At 25 min after pacing was started, BRL37344 (9 $\mu \mathrm{g} / \mathrm{kg}$ ) or SR59230A (0.5 mg/kg) was initially administered by pump infusion for at least $30 \mathrm{~min}$, followed by infusion twice a day throughout the study period $[10,12,19]$. The control group was given the vehicle solvent of the $\beta 3$-AR agonist and antagonist. All chemicals were purchased from Sigma-Aldrich.

At the end of the experimental procedure, the rabbits were anesthetized (ketamine, $30 \mathrm{mg} / \mathrm{kg}$, i.m.) and echocardiography measurements were taken. Rabbits were euthanized (ketamine, $105 \mathrm{mg} / \mathrm{kg}$; xylazine, $15 \mathrm{mg} / \mathrm{kg}$, i.m.) and blood samples were collected from the hearts. The left and right atrial tissues were rapidly isolated, frozen in liquid nitrogen and stored at $-80^{\circ} \mathrm{C}$ for further molecular biological experiments, or immersed in the $10 \%$ formaldehyde for subsequent histology staining.

Induction of $A F$ and recording of atrial effective refractory period (AERP)

Initially a train of eight basic stimuli (S1) followed by a premature stimulus (S2) with an S1-S2 interval was given. The S1-S2 interval was decreased by $5 \mathrm{~ms}$ decrements until S2 failed to produce the atrial response. The S1-S2 interval was then increased by $5 \mathrm{~ms}$ and decreased in $2 \mathrm{~ms}$ steps until S2 failed to capture the depolarization. AERP was defined as the longest S1-S2 interval failing to initiate atrial depolarization, and was measured at a basic cycle lengths (BCLs) (200 ms). The mean value of three AERPs was used for data analysis. After AERP measurement, AF was induced with a train of $10 \mathrm{~Hz}, 2 \mathrm{~ms}$ stimuli to the right atrium at four times the threshold current. AF was defined as a rapid and irregular atrial rhythm. The atrial electrogram morphology and surface ECG were recorded.

Measurements of adenosine 5'-triphosphate (ATP) and free fatty acid (FFA)

ATP and FFA concentration measurement kits were purchased from Jiancheng Biological Technical Institute (China). All procedures were performed following the manufacturer's instructions. Frozen tissues were homogenized in a saline buffer and centrifuged at $10000 \mathrm{~g}$ for $5 \mathrm{~min}$. Blood samples were centrifuged at $2000 \mathrm{~g}$ to obtain plasma. Tissue ATP and FFA and plasma FFA were measured by spectrophotometer colorimetry at $636 \mathrm{~nm}$ and $440 \mathrm{~nm}$, respectively [20,21]. 
Table 1. Primers for real-time PCR

\begin{tabular}{|c|c|c|}
\hline$\beta$-actin & $\begin{array}{l}\text { forward primer } \\
\text { reverse primer }\end{array}$ & $\begin{array}{l}\text { 5' GTCAGGTCATCACTATCGGCAAT 3' } \\
\text { 5' AGAGGTCTTTACGGATGTCAACGT3' }\end{array}$ \\
\hline$\beta 3$-ARs & $\begin{array}{l}\text { forward primer } \\
\text { reverse primer }\end{array}$ & $\begin{array}{l}\text { 5'CACGCTGGGGCTCATTAT3' } \\
\text { 5'TGAAGGCAGAGTTGGCAT3' }\end{array}$ \\
\hline PGC-1 & $\begin{array}{l}\text { forward primer } \\
\text { reverse primer }\end{array}$ & $\begin{array}{l}\text { 5'GAGAAGCGGGAATCGGAAAG3' } \\
\text { 5'GCATCACAGGTGTATCGGTAGGT3' }\end{array}$ \\
\hline $\operatorname{PPAR} \alpha$ & $\begin{array}{l}\text { forward primer } \\
\text { reverse primer }\end{array}$ & $\begin{array}{l}\text { 5'GTCGCCATCCGCATCTTT3' } \\
\text { 5'AGGACCCCGTCTTTATTCATC3' }\end{array}$ \\
\hline GLUT-4 & $\begin{array}{l}\text { forward primer } \\
\text { reverse primer }\end{array}$ & $\begin{array}{l}\text { 5' AGAGGGAATGCGAAAGC3' } \\
\text { 5'GGTCAAGAGCCTGTGGG3' }\end{array}$ \\
\hline CD36 & $\begin{array}{l}\text { forward primer } \\
\text { reverse primer }\end{array}$ & $\begin{array}{l}\text { 5'TTGGTGTGTTTTATCCTAC3' } \\
\text { 5'GGTTCCAGTCTCATTAAGCC3' }\end{array}$ \\
\hline СРТ-1 & $\begin{array}{l}\text { forward primer } \\
\text { reverse primer }\end{array}$ & $\begin{array}{l}\text { 5'GTGAAGAAACAACCCCCAGA3' } \\
\text { 5'GGAAGCACTTGAGACAAGCC3' }\end{array}$ \\
\hline
\end{tabular}

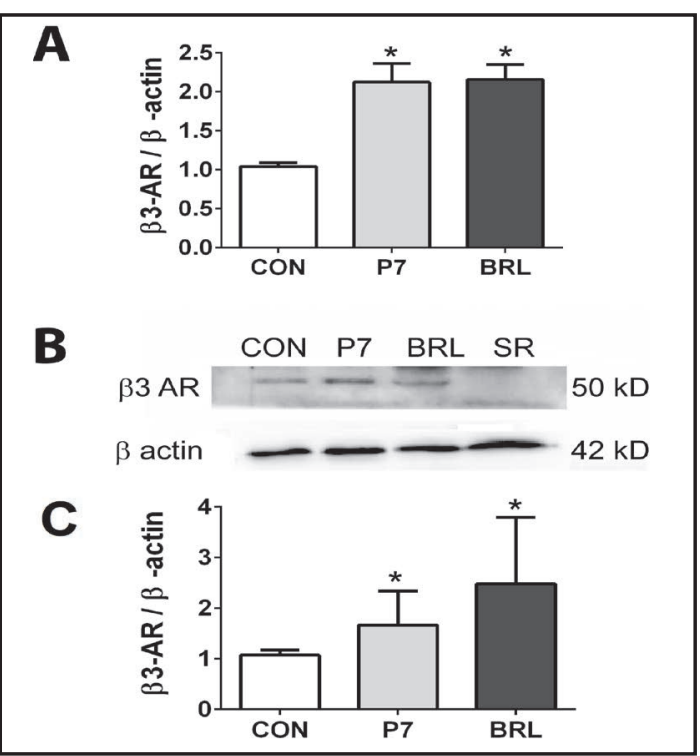

Fig. 1. The mRNA and protein levels of $\beta 3-A R$ in the AF heart. A) mRNA expression of $\beta 3$-AR in the control, P7, and BRL groups. B) WB results for $\beta 3$-AR protein levels. C) Quantitation of $\beta 3-A R$ protein levels. $* p<0.05$ vs. control group.

\section{Oil red $O$ staining}

Accumulation of lipid droplets in cardiac myocytes was observed by Oil Red 0 staining. Ten-micronthick frozen sections were obtained with a Leica CM1850, and recovered at room temperature for $3-5 \mathrm{~min}$. Lipid droplets are shown in red and nuclei in blue.

\section{Periodic acid Schiff (PAS) staining}

Atrial tissues were cut into small pieces and immersed in $10 \%$ formaldehyde for $24 \mathrm{~h}$. Tissues were then embedded in a paraffin block and cut into $5-\mu$ m-thick sections. PAS staining was performed to evaluate glycogen distribution in myocytes.

\section{Western blotting (WB)}

Total proteins were extracted from tissues, separated by SDS-PAGE (8-15\%), and transferred onto polyvinylidene difluoride membranes, as described previously $[11,14]$. Primary antibodies for $\beta 3$-AR (1:100, Santa Cruz), CD36 (1:100, Santa Cruz), mCPT-1 $\alpha$ (1:100, Santa Cruz), GLUT-4 (1:500, Abcam), PPAR $\alpha$ (1:100, Santa Cruz), or PGC-1 $\alpha$ (1:500, Abcam) were used to detect specific proteins. Antibody against $\beta$-actin (1:5000, ZSGB Biological Company) was used as an internal control. Horseradish peroxidase-conjugated anti-goat (1:1000, Beyotime) or anti-mouse (1:1000, ZSGB Biological Company) IgGs were used to bind the primary antibodies. After 4 TBST washes, the blots were developed with chemiluminescence, and were digitized using Bio-Rad image analysis software.

\section{Real-time PCR}

Total RNA was obtained by TRIzol (Invitrogen) extraction. Reverse transcription was carried out using the AccuPower ${ }^{R}$ RocketScript ${ }^{\mathrm{TM}}$ RT Premix Kit (Bioneer). Quantitative real-time PCR was performed with SYBR Green (TianGen) incorporation on an ABI 7500 Real Time PCR system (Applied Biosystems). $\beta$-Actin was used as an internal gene expression control. The primers used in this study are summarized in Table 1.

\section{Data analysis and statistics}

Data are expressed as mean \pm S.D. Differences between groups were evaluated by analysis of variance (ANOVA) followed by Dunnett's T3 or LSD post hoc test in the SPSS 17.0 software. Statistically significant differences were defined as $p<0.05$. 


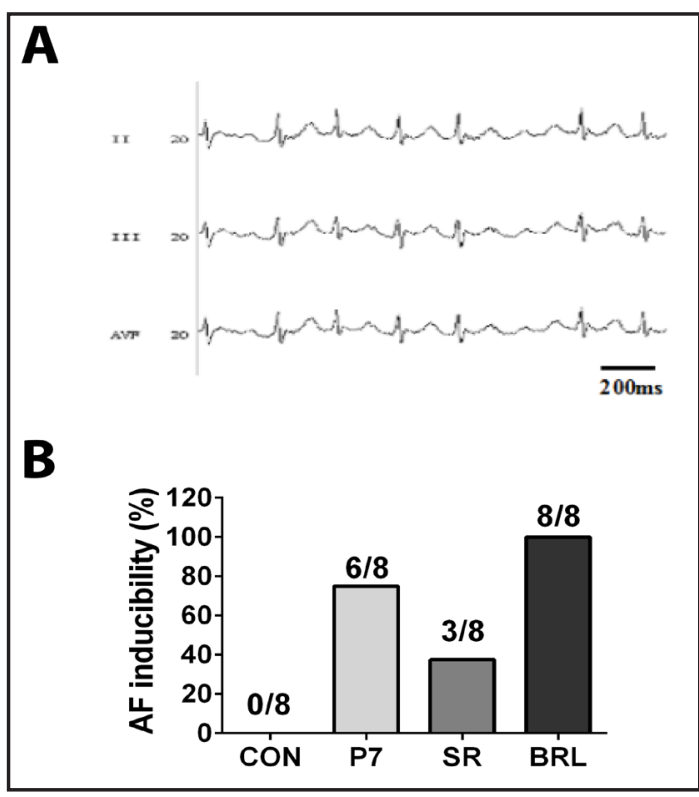

Fig. 2. Rapid pacing induced $A F$ in the rabbit. A) AF was induced after rapid-pacing. B) AF induction rate in the control, P7, SR, and BRL groups.

Fig. 4. Comparison of ATP concentration among groups. Quantitative result of ATP concentration among groups. ${ }^{* *} \mathrm{p}<0.01$ vs. control group.

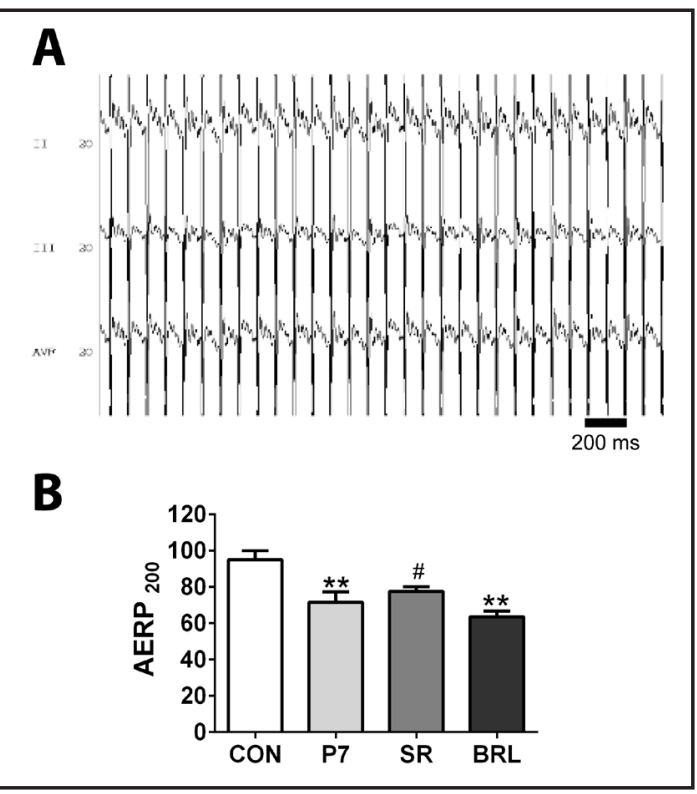

Fig. 3. Comparison of AERP among groups. A) Surface ECG recording for pacing rhythm. B) Quantitative result of AER for each group. ${ }^{* *} \mathrm{p}<0.01$ vs. control group, \#p $<0.05$ vs. P7 group.

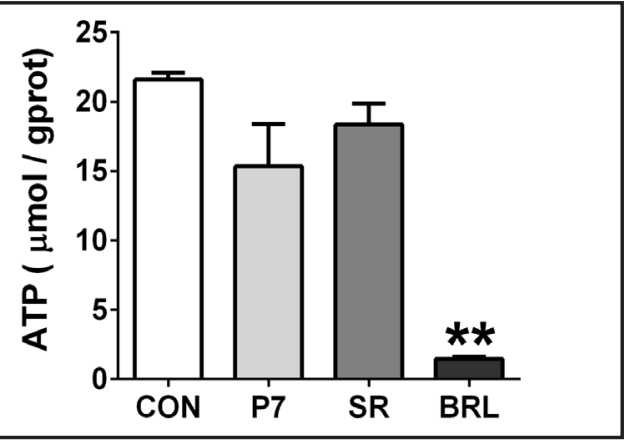

\section{Results}

Upregulation of $\beta 3-A R$ in rabbits with pacing-induced $A F$

The RT-PCR result showed that the $\beta 3-A R$ mRNA levels in the pacing group (P7) and in the $\beta 3$-AR agonist treated group (BRL) were significantly higher than in the control group (CON) (Fig. 1A). WB results also revealed a significant upregulation of $\beta 3$-AR protein in the P7 and BRL groups (Fig. 1B and C) compared to the control group. This result is consistent with Sheng's previous report that $\beta 3$-AR expression increased in a canine model of pacinginduced $A F$ [11]. Interestingly, expression of $\beta 3-A R$ protein in the group treated with 0.5 $\mathrm{mg} / \mathrm{kg}$ of $\beta 3$-AR antagonist, SR59230A, was barely detected by WB (Fig. $1 \mathrm{~B}$ ), implying that application of the $\beta 3$-AR antagonist might completely inhibit $\beta 3$-AR expression.

\section{Inhibition of $\beta 3-A R$ decreased inducibility of $A F$ in the rabbit model}

The pacing rhythm was recorded at $600 \mathrm{bpm}$ using surface ECG, and a representative trace is presented in Figure $2 \mathrm{~A}$. The AF induction rate in rabbits from each group is summarized in Figure 2B. None of the rabbits $(0 / 8)$ in the control group had AF. In the pacing group (P7), 6 out of $8(75 \%)$ rabbits had induced AF. All rabbits $(8 / 8,100 \%)$ in the BRL group treated with $\beta 3$-AR agonist BRL37344 had induced AF. In contrast, the SR group treated with the $\beta 3$ AR antagonist, SR59230A, showed only 37.5\% (3/8) AF induction. This result suggests that inhibition of $\beta 3$-AR using SR59230A decreased the rate of AF inducibility. 


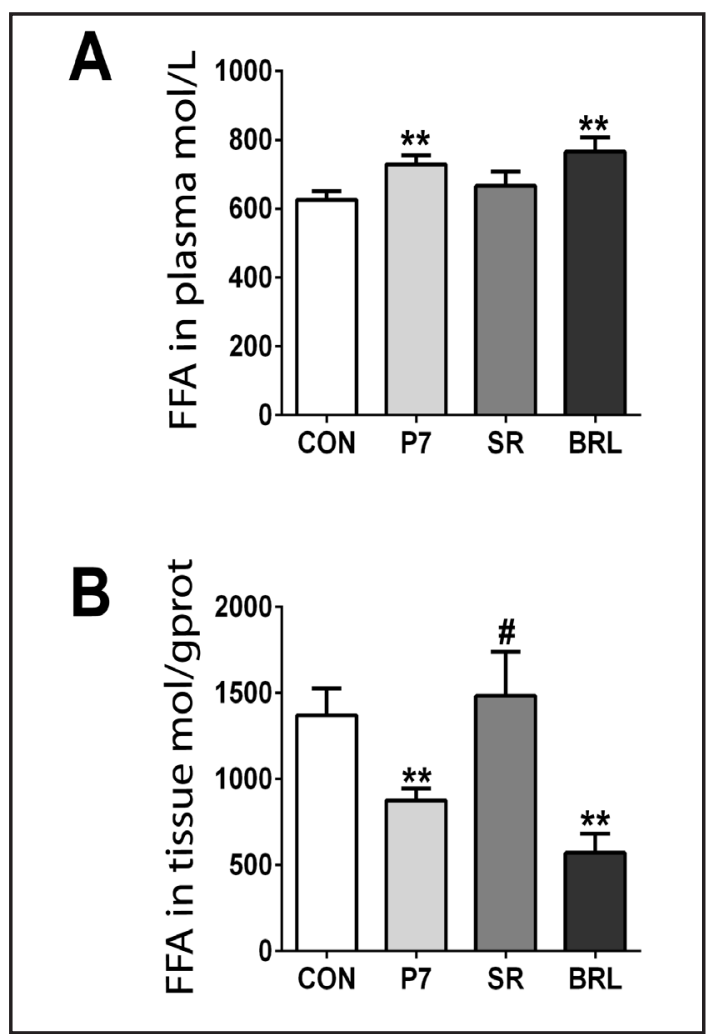

Fig. 5. Comparison of plasma and tissue fatty acid concentrations among groups. A) Plasma fatty acid concentration. B) Tissue fatty acid concentration. ${ }^{* *} \mathrm{p}<0.01$ vs. control group; \#p $<0.05$ vs. P7 group.

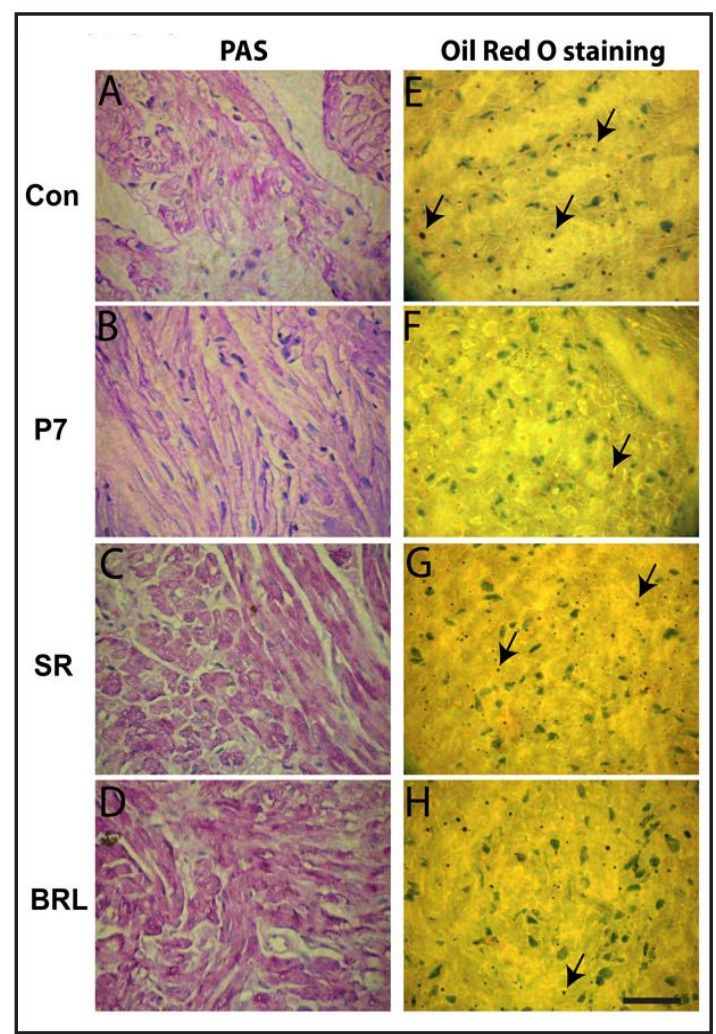

Fig. 6. PAS and Oil red 0 staining in cardiac tissue. (A-D) PAS staining was used to compare the glycogen accumulation in cardiac tissue. (E-H) Oil Red $\mathrm{O}$ staining was used to visualize lipid droplets in cardiac myocytes. Lipid droplets are light red and nuclei are blue. Scale bar $=5 \mu \mathrm{m}$ in panel $\mathrm{H}$.

Inhibition of $\beta 3-A R$ reversed rapid pacing-induced AERP reduction

Further, we compared the AERP among groups. Representative $\mathrm{AERP}_{200}$ recording are presented in Figure 3A. The pacing group (P7) had a significantly shortened AERP 200 compared to the control group (71.67 \pm 5.77 vs. $95.00 \pm 5.00 \mathrm{~ms}, p<0.01$, Fig. 3B). Treatment with the agonist, BRL37344, further decreased AERP ${ }_{200}$ compared to the P7 group (63.67 \pm 3.22 vs. $71.67 \pm 5.77 \mathrm{~ms}, p=0.06)$, and significantly reduced $\mathrm{AERP}_{200}$ compared to the control group ( $63.67 \pm 3.22$ vs. $95.00 \pm 5.00 \mathrm{~ms}, p<0.01)$. In contrast, $\beta 3$-AR antagonism with SR59230A reversed the pacing-induced AERP ${ }_{200}$ reduction to some extent $(77.67 \pm 2.52$ vs. $71.67 \pm 5.77 \mathrm{~ms}$ in the P7 group, $p<0.01$, Fig. $3 \mathrm{~B}$ ).

\section{Inhibition of $\beta 3-A R$ reversed ATP reduction in the atria of rabbits with $A F$}

ATP concentration in the rabbit atrial issue was compared among groups (Fig. 4). Compared to the control group, the P7 group showed a $28.96 \%$ reduction in the ATP concentration $(15.33 \pm 3.06$ vs. $21.58 \pm 0.52 \mu \mathrm{mol} /$ gprot, $p=0.20)$. In the SR group, application of $\beta 3$-AR antagonist resulted in a higher level of ATP compared to that in the P7 group, although the difference was not statistically different $(p=0.17)$. Application of the $\beta 3$-AR agonist, BRL37344, resulted in a significantly decreased ATP content that dropped to $6.81 \%$ of the CON group (1.47 \pm 0.15 vs. $21.58 \pm 0.52 \mu \mathrm{mol} /$ gprot, $p<0.001$ ) and $9.59 \%$ of the P7 group (1.47 \pm 0.15 vs. $15.33 \pm 3.06 \mu \mathrm{mol} /$ gprot, $p<0.001)$.

Inhibition of $\beta 3-A R$ reversed plasma and atrial tissue FFA alternations in rabbits with $A F$

Next, we evaluated the FFA level in the plasma and atrial tissue of the rabbits. Compared to the control group, the P7 group with rapid pacing-induced AF had a significantly increased 


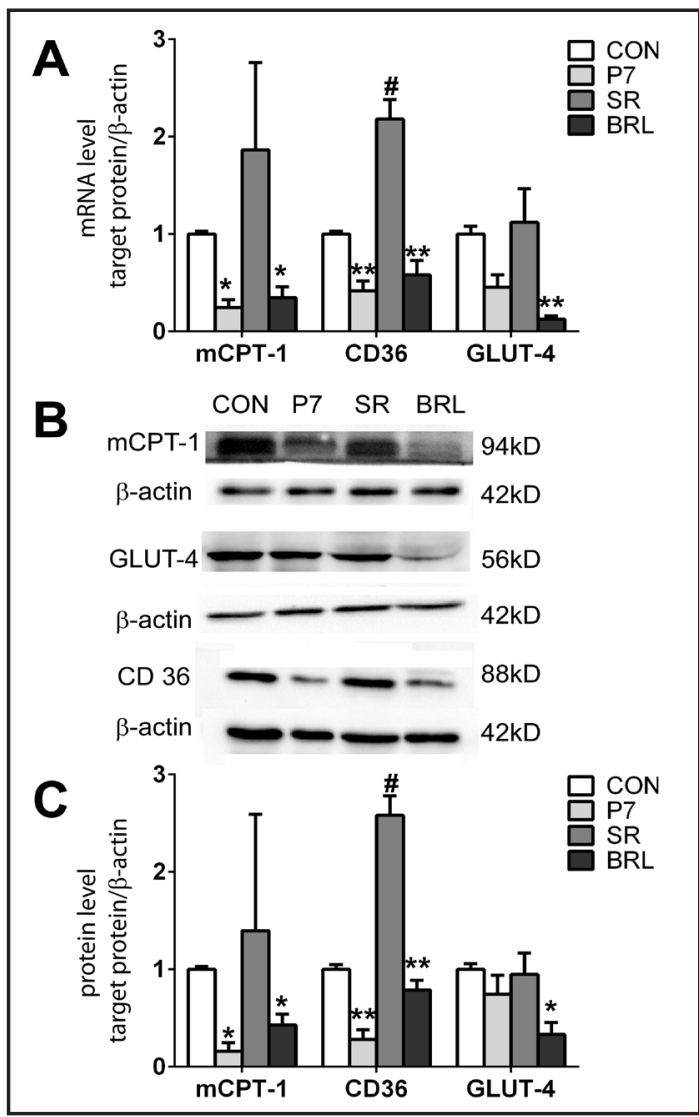

Fig. 7. Gene and protein levels of CPT-1, CD36, and GLUT-4. A) Gene expression levels of CPT-1, CD36, and GLUT-4 among groups. B) WB results for CPT1, CD36, and GLUT-4 protein expression. C) Quantitation of CPT-1, CD36, and GLUT-4 protein levels in four groups. ${ }^{*} \mathrm{p}<0.05$ and ${ }^{* *} \mathrm{p}<0.01$ compared to the CON group, \#p $<0.05$ compared to the P7 group. mCPT-1: muscle carnitine-palmitoyltransferase I; GLUT-4: glucose transporter-4.

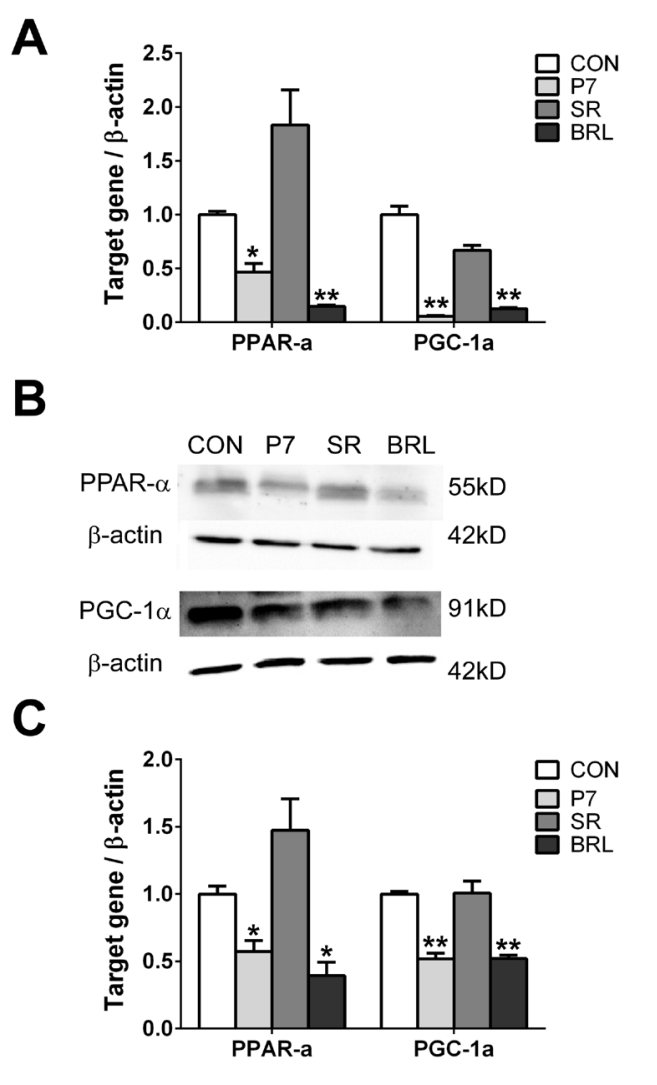

Fig. 8. Gene and protein levels of PPAR $\alpha$ and PGC- $1 \alpha$. A) Gene expression levels of PPAR $\alpha$ and PGC1- $\alpha$. B) WB results for PPAR $\alpha$ and PGC1- $\alpha$ protein level. C) Quantitation of PPAR $\alpha$ and PGC1- $\alpha$ protein levels. *p $<0.05$ and ${ }^{* *} \mathrm{p}<0.01$ compared to the CON group; $\# p<0.05$ and \#\#p $<0.01$ compared to the P7 group. PPAR $\alpha$ : peroxisome proliferator-activated receptor- $\alpha$; PGC1- $\alpha$ : PPAR co-activator.

plasma FFA concentration (729.30 \pm 29.08 vs. $625.90 \pm 25.05 \mu \mathrm{mol} /$ gprot, $p<0.01$, Fig. 5 A) . Inhibition of the $\beta 3$-AR in the SR group abolished the AF-induced increase of the plasma FFA and resulted in levels similar to those seen in the CON group (666.51 \pm 41.57 vs. $625.90 \pm$ $25.05 \mu \mathrm{mol} /$ gprot, $p=0.2$ ). On the contrary, activation of $\beta 3$-AR using BRL37344 increased plasma FFA significantly in the BRL group compared to the CON group (765.52 \pm 41.10 vs. $625.90 \pm 25.05 \mu \mathrm{mol} /$ gprot, $p<0.01$ ), but the BRL group showed no difference compared to the P7 group (765.52 \pm 41.10 vs. $729.30 \pm 29.08 \mu \mathrm{mol} /$ gprot, $p=0.23)$.

Interestingly, compared to the plasma FFA alternations, the tissue FFA changes among groups showed an opposite trend. The P7 group exhibited significantly less tissue FFA than the CON group (876.65 \pm 68.05 vs. $1371.00 \pm 154.50 \mu \mathrm{mol} /$ gprot, $p<0.01)$. Activation of $\beta 3$ AR led to a dramatic decline in tissue FA (571.2 \pm 111.8 vs. $1371.00 \pm 154.50 \mu \mathrm{mol} /$ gprot in CON group, and $571.2 \pm 111.8$ vs. $1483.99 \pm 256.84 \mu \mathrm{mol} /$ gprot in SR group, both $p<0.01$ ). SR59230A treatment partly restored the tissue FFA level $(1483.99 \pm 256.84$ vs. $1371.00 \pm$ $154.50 \mu \mathrm{mol} /$ gprot in the CON group, $p=0.42$, Fig. 5B).

Alterations in the accumulation of glycogen and lipid droplets in the cardiac tissue

Glycogen accumulation is a prominent manifestation of AF structural remodeling. Using PAS staining (Fig. 6), we observed that the P7 group had obvious glycogen accumulation 
compared to the control group (Fig. 6 A), as seen by an increase in PAS staining (Fig. 6 B) in the cardiac tissue. Application of SR59230A in the pacing animals alleviated the glycogen accumulation (Fig. $6 \mathrm{C}$ ), indicating that inhibition of $\beta 3$-AR improved AF structural remodeling. Oil red $\mathrm{O}$ staining was used to compare lipid droplet accumulation in the cardiac tissue among groups (Fig. 6 E-H). Compared to the control group, the P7 and BRL groups both showed fewer lipid droplets (in red, arrows in Fig. $6 \mathrm{~F}$ and H). The SR group showed more Oil red 0-positive cells (Fig. $6 \mathrm{G}$ ). These results indicated that pacing-induced AF led to glycogen accumulation and decreased lipid droplets in the cardiac tissue. Activation of $\beta 3$ AR exhibited similar effects as pacing-induced AF on structural remodeling, while inhibition of $\beta 3$-AR partially reversed the alternations.

\section{Alterations in the gene and protein levels of glucose and fatty acid transport}

To confirm whether AF-induced changes in glycogen and lipid accumulation in cardiac tissue are related to altered fatty acid and glucose metabolism, we further compared the mRNA and protein levels of the key regulators, CPT-1 and CD36, in fatty acid metabolism, and GLUT- 4 in glucose metabolism. Our results showed that both gene and protein levels of CPT-1 and CD36 were significantly reduced in the P7 group ( $p<0.05$, Fig. 7 A-C), suggesting decreased fatty acid metabolism after AF induction. The SR group with $\beta 3-\mathrm{AR}$ inhibition showed significantly higher CPT-1 and CD36 levels than the P7 group $(p<0.05)$ but no statistically significant difference compared to the control group. The BRL group showed significant decreases in both gene and protein levels of CPT-1 and CD36 compared to the control and SR group ( $p<0.05$, Fig. 7).

Compared to the control group, GLUT-4 mRNA and protein levels were decreased in the P7 group, but the decline in its protein level in the P7 group did not show any statistical significance $(p=0.2)$. BRL37344 infusion significantly reduced GLUT-4 protein $(p<0.05)$ and mRNA levels $(p<0.01)$ compared to the control group. The GLUT-4 expression in the BRL group was also significantly lower than that in the SR group $(p<0.01$, for both gene and protein levels, Fig. 7).

SR59230A inhibited pacing-induced decreases in PPAR $\alpha / P G C-1 \alpha$

PPAR $\alpha$ and its co-activator PGC- $1 \alpha$ constitute the key signaling pathway involved in the energy metabolism. In this study, RT-PCR and WB results showed that both mRNA and protein levels of PPAR $\alpha$ and PGC- $1 \alpha$ were significantly reduced in the P7 group, suggesting that pacing-induced metabolic remodeling involved downregulation of PPAR $\alpha /$ PGC- $1 \alpha$ signaling. Inhibition of $\beta 3-A R$ using SR59230A restored the pacing-induced decline in both protein and gene levels. The SR group showed similar levels of PPAR $\alpha$ and PGC- $1 \alpha$ to those of the control group (Fig. 8). In contrast, activation of $\beta 3$-AR by BRL37344 infusion aggravated the pacing-induced reduction of PPAR $\alpha / \mathrm{PGC}-1 \alpha$ signaling. All of these results suggest that the PPAR $\alpha /$ PGC- $1 \alpha$ signaling pathway might be the relevant down-stream molecular machinery in $\beta 3$-AR mediated metabolic remodeling of the rabbit AF model.

\section{Discussion}

In this study, we reported that in the rabbit model of pacing-induced AF, the expression of $\beta 3-A R$ was increased, and activation of $\beta 3-A R$ mediated metabolic-related protein remodeling. Activation of $\beta 3$-AR by an exogenous agonist decreased the adverse effects of AF, possibly by increasing myocardial substrate utilization, while inhibition of $\beta 3$-AR partially decreased inducibility of $A F$, and reversed the pacing induced AERP reduction and ATP concentration. $\beta 3$-AR mediated changes in glycogen and lipid droplet accumulation and altered glucose and fatty acid metabolism might be responsible for metabolic-related protein remodeling. $\beta 3$-AR dependent regulation of PPAR $\alpha$ and PGC- $1 \alpha$ levels suggests that the PPAR $\alpha /$ PGC- $1 \alpha$ signaling pathway might be the down-stream molecular machinery of the $\beta 3$-AR mediated metabolic-related protein remodeling. All of these results suggest a 
critical role of $\beta 3$-AR in regulating AF-induced metabolic-related protein remodeling in a rabbit model of pacing-induced $\mathrm{AF}$.

\section{$\beta 3-A R$ activation exacerbates cardiac metabolism during $A F$}

The $\beta$-AR system plays an important role in cardiac physiology and pathology. In contrast to the $\beta 1$ - and $\beta 2-\mathrm{AR}, \beta 3-\mathrm{AR}$ has gained more attention because of its disputative therapeutic perspective. $\beta 3$-AR is upregulated during heart failure [22]. However, its role remains debatable. Several studies have reported that activation of $\beta 3$-AR can prevent heart failure; in contrary, some studies reported deleterious effects of $\beta 3$-AR agonists. A clinical trial demonstrated that administration of nebivolol, a $\beta 3$-AR agonist, improved hemodynamic parameters in patients with heart failure [23]. However another trial also reported that nebivolol failed to improve outcomes in patients with stable heart failure and co-existing AF [24]. Furthermore, activation of $\beta 3$-AR affects energy metabolism during the pathogenesis of the heart failure, eventually contributing to cardiac dysfunction [21]. $\beta 3$-AR antagonist SR59230A attenuates the imbalance of systemic and myocardial oxygen transport induced by dopamine in newborn lambs [25].

In this study, we found that the $\beta 3$-AR was upregulated after 7-day pacing and further upregulated after administration of BRL37344. The finding of $\beta 3$-AR protein expression in the BRL group was consistent with two studies in which $\beta 3$-AR expression increased significantly during exposure to isoproterenol and BRL37344 respectively [26, 27]. Further activation of $\beta 3$-AR pharmacologically increased AF induction, while blockage of $\beta 3-A R$ reduced the rate of $A F$ induction, supporting the idea that $\beta 3-A R$ is not only related to the heart failure, but is also related to the progression of AF. This study provides evidence for the potential use of $\beta 3-\mathrm{AR}$ antagonists to reduce the incidence of AF.

Interestingly, the expression of $\beta 3-A R$ was barely detected in the SR group. This might be explained by the inhibitory effect of $\beta 3$-AR antagonism on $\beta 3$-AR expression. As the primary antibody used for WB effectively reacted with rabbit heart tissue, we speculate that the current dose of $\beta 3$-AR antagonist may largely or completely inhibit the expression of $\beta 3$ AR. This observation is also consistent with Sheng's report in which administration of the $\beta 3$-AR antagonist L748337 decreased $\beta 3$-AR protein expression [11]. As L748337 has weak partial agonist activity for cAMP accumulation, in this experiment we used another $\beta 3$-AR antagonist, SR59230A, which is a classic competitive antagonist for cAMP accumulation [28].

In 2004, Bilsen et al. proposed the concept of cardiac energy metabolic remodeling, suggesting altered high-energy-phosphate content and mitochondrial function and an increased dependence on glucose as substrate instead of fatty acids [13]. Recent studies have also reported the cardiac hypermetabolic state during AF [29]. White et al. showed that the atrial coronary blood flow reserve ability decreased markedly because of atrial oxygen consumption, and coronary flow increased almost three-fold after induction of AF [30, 31]. Moreover, the energy production efficiency declined for fatty acid oxidation. Theoretically, fatty acid oxidation produces more ATP but consumes more oxygen than glucose oxidation [32]. In order to compensate for the hypermetabolic state and save oxygen, fatty acid oxidation might decrease. In this study, we observed that although the ATP level and GLUT-4 expression decreased in the AF group, but they were not statistically different from those of the control group. This may be due to the higher ATP production efficiency of fatty acid oxidation. In the early stage of AF, although fatty acid oxidation decreased it could still provide enough ATP, and substrate preference for fatty acids possibly still remained. Therefore, the ATP concentration showed no dramatic change. The other reason may be related to retained heart function in the early phase of the arrhythmia. In our experiment, using transthoracic echocardiography we did find that the cardiac function remained normal in all animals (data are not shown). However, changes in metabolism resulted in an elevated free fatty acid concentration in the plasma that has been shown to cause an oxygen-wasting effect on the myocardium and result in lipotoxicity to the heart [32].

Activation of $\beta 3$-AR decreased CD36 and GLUT-4 significantly, and led to a reduction of fatty acid and glucose transportation, following reduction of CPT- 1 , which indicates reduced 
fatty acid metabolism, resulting in a significant decrease in the ATP level. This suggests that activation of $\beta 3$-AR might aggravate cardiac load and notably increase cardiac oxygen and energy demand, eventually causing disturbed energy metabolism. The observation that the B3-AR antagonist, SR59230A, could mostly reverse the ATP production and increase fatty acid and glucose oxidation further supports this hypothesis. To some extent, inhibition of $\beta 3-\mathrm{AR}$ reverses the effect, possibly by producing more ATP and consuming less oxygen.

$P P A R \alpha / P G C-1 \alpha$ involvement in the $\beta 3$-AR-mediated metabolic remodeling of AF

Nuclear receptors, PPAR $\alpha, \beta$, and $\alpha$ as well as their co-activator PGC- $1 \alpha$ have been considered as the core regulator of metabolic remodeling of the heart. The transcriptional control of genes encoding fatty acid and glucose oxidation are largely mediated by PPAR and PGC-1 $\alpha$ [33]. For instance, CPT- 1 expression can be induced by co-activation of PGC-1 $\alpha$ and PPAR $\alpha[34,35]$. Decreased PGC- $1 \alpha$ is a common feature of acquired cardiac disease such as cardiac hypertrophy and heart failure [36]. PPAR $\alpha$-deficient mice also display decreased cardiac fatty acid oxidation rates, and increased glucose oxidation rates, which may result in toxic effects on accumulated lipid metabolites and energetic and functional abnormalities [37].

In this study, we observed $\beta 3$-AR activation-dependent regulation of mCPT- 1 and PGC- $1 \alpha$ expression in cardiac tissue with AF. Moreover, the PPAR $\alpha /$ PGC- $1 \alpha$ signaling pathway could also be influenced by pharmacological intervention of the $\beta 3-A R$. These results indicated that in the rabbit model of pacing-induced AF, PPAR $\alpha / \mathrm{PGC}-1 \alpha$ signaling might be involved in the downregulation of mCPT- 1 and PGC- $1 \alpha$, and altered energy metabolism in response to $\beta 3$ AR activation. Reduced fatty acid and glucose oxidation might ultimately result in hypoxiaischemia state in the heart. The fact that inhibition of the $\beta 3$-AR could enhance PGC- $1 \alpha$ / PPAR $\alpha$ signaling and restore energy metabolism further supported the idea that a PGC- $1 \alpha$ / PPAR $\alpha$ component might be the effective down-stream machinery in response to AF-induced activation of $\beta 3-\mathrm{AR}$ and consequent metabolic remodeling.

Moreover, PPAR $\alpha$ alteration was found in diabetic hearts and led to remodeling of a wide variety of ion channels, most prominently $\mathrm{I}_{\text {to }}$; this contributes to repolarization abnormalities and predisposes patients to arrhythmias [38]. We also previously reported that $\beta 3$-AR activation increases $I_{\text {to }}$ in rapidly paced atrial myocytes [10] and reduced AERP. In this study, $\beta 3$-AR inhibition reversed the AF-induced decrease of AERP also suggests that the PPAR $\alpha$ / PGC- $1 \alpha$ signaling pathway contributes to the $\beta 3$-AR-mediated metabolism remodeling.

\section{Limitations}

It has been reported that a decrease in the atrial phosphocreatine level occurred as early as 25 min after AF induction and became significant in 1 week [39]. Therefore, in this study agonist or antagonist treatment was performed at $25 \mathrm{~min}$ after forced heart pacing. However, the level of phosphocreatine might vary over time. In this study, we only measured energy metabolism in the early phase of $\mathrm{AF}$, the time-dependent effect in metabolic remodeling will need further exploration.

Thus far, three types of $\beta$-ARs have been reported in human and rodent hearts. In this study, for simplicity, we investigated the effect of $\beta 3$-AR on metabolic remodeling in the presence of nadolol, an antagonist of $\beta 1$ - and $\beta 2-A R$, to exclude interference from other the two subtypes. However, it will be intriguing to identify their interactions during the progress of $\mathrm{AF}$ in the future.

\section{Conclusion}

This study provided evidence for a regulating role of $\beta 3$-AR in AF-induced metabolismrelated protein remodeling. Pacing-induced AF causes activates the $\beta 3-\mathrm{AR}$ and disrupts energetic metabolism-related proteins. Inhibition of $\beta 3-A R$ suppresses AF-induced metabolism-related protein disruption via regulating PPAR $\alpha /$ PGC- $1 \alpha$ pathway. All of these results, together with our previous reports that $\beta 3$-AR inhibition could block structural [11] 
and electrical [10] remodeling and partially alleviate metabolism-related protein remodeling in rodent models, suggest that the $\beta 3$-AR might be a potential novel target for AF therapy.

\section{Conflict of Interest}

\section{Authors state no conflict of interest.}

\section{Acknowledgements}

This work was supported by National Natural Science Foundation of China (grant number 81270252, 30971251, 81070160 and 81100071), Foundation for Innovative Research Groups of the National Natural Science Foundation of China (81121003), Scientific Research Fund of Heilongjiang Provincial Education Department(grant number 12521206), and the Program for New Century Excellent Talents In University (grant number NCET-090132).

\section{References}

1 Kumar S, Teh AW, Medi C, Kistler PM, Morton JB, Kalman JM: Atrial remodeling in varying clinical substrates within beating human hearts: relevance to atrial fibrillation. Prog Biophys Mol Biol 2012;110:278-294.

2 Wijffels MCEF, Kirchhof CJHJ, Dorland R, Allessie MA: Atrial fibrillation begets atrial fibrillation: A study in awake chronically instrumented goats. Circulation 1995;92:1954-1968.

- Allessie M, Ausma J, Schotten U: Electrical, contractile and structural remodeling during atrial fibrillation. Cardiovasc Res 2002;54:230-246.

- Mayr M, Yusuf S, Weir G, Chung Y, Mayr U, Yin X, Ladroue C, Madhu B, Roberts N, Souza A, Fredericks S, Stubbs M, Griffiths J, Jahangiri M, Xu Q and Camm A: Combined metabolomic and proteomic analysis of human atrial fibrillation. J Am Coll Cardiol 2008;51:585-594.

-5 Aksnes TA, Schmieder RE, Kjeldsen SE, Ghani S, Hua T, Julius S: Impact of new-onset diabetes mellitus on development of AF and heart failure in high-risk hypertension (from the Value Trial). Am J Cardiol 2008;101:634-638. Barth A, Tomaselli G: Cardiac metabolism and arrhythmias. Circ Arrhythm Electrophysiol 2009;2:327-335. Rozec B, Gauthier C: $\beta 3$-adrenoceptors in the cardiovascular system, putative roles in human pathologies. Pharmacol Ther 2006;111:652-673. Conrath CE, Opthof T: $\beta 3$-adrenoceptors in the heart. Cardiovasc Res 2002;56:353-356. Dessy C, Balligand J: $\beta 3$-adrenergic receptors in cardiac and vascular tissues: emerging concepts and therapeutic perspectives. Adv Pharmaco 2010;59:135-163.

10 Yu J, Li W, Li Y, Zhao J, Wang L, Dong D, Pan Z, Yang B: Activation of $\beta 3$-adrenoceptor promotes rapid pacing-induced atrial electrical remodeling in rabbits. Cell Physiol Biochem 2011;28:87-96.

-11 Sheng L, Shen Q Huang K, Liu G, Zhao J, Xu W, Liu Y, Li W, Li Y: Up-regulation of $\beta 3$-adrenergic receptors contributes to atrial structural remodeling in rapid pacing induced atrial fibrillation canines. Cell Physiol Biochem 2012;30:372-381.

12 Audigane L, Kerfant B, Harchi A, Lorenzen-Schmidt I, Toumaniantz G, Cantereau A, Potreau D, Charpentier F, Noireaud J, Gauthier C: Rabbit, a relevant model for the study of cardiac $\beta 3$-adrenoceptors. Exp Physiol 2009;94:400-411.

13 Bilsen M, Smeets P, Gilde AJ, Vusse G: Metabolic remodelling of the failing heart: the cardiac burn-out syndrome? Cardiovasc Res 2009;61:218-226.

-14 Steinbusch LK, Schwenk RW, Ouwens DM, Diamant M, Glatz JF, Luiken JJ: Subcellular trafficking of the substrate transporters GLUT4 and CD36 in cardiomyocytes. Cell Mol Life Sci 2011;68:2525-2538.

-15 Razeghi P, Young M, Ying J, Depre C, Uray IP, Kolesar J, Shipley G, Moravec CS, Davies PJ, Frazier OH, Taegtmeyer H: Downregulation of metabolic gene expression in failing human heart before and after mechanical unloading. Cardiology 2002;97:203-209.

16 Kolwicz S Jr, Tian R: Glucose metabolism and cardiac hypertrophy. Cardiovasc Res 2011;90:194-201.

17 Kerner J, Hoppel C: Fatty acid import into mitochondria. Biochim Biophys Acta 2000;1486:1-17. 


\section{Cellular Physiology Cell Physiol Biochem 2013;32:1631-1642

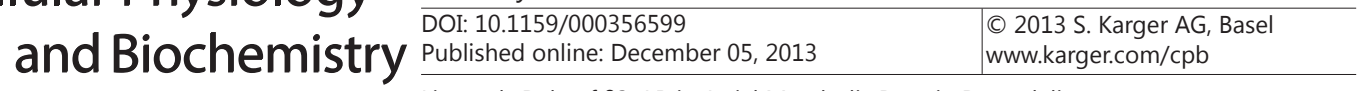

Liu et al.: Role of $\beta 3-A R$ in Atrial Metabolic Protein Remodeling

18 Tian Y, Zhu SJ, Wang J, Li ZK, Song R, Nie L: Expressions of $\beta 3$-adrenoceptor and peroxisome proliferatoractivated receptor alpha in human failing heart. Zhonghua Xin Xue Guan Bing Za Zhi 2007;35:607-610.

19 Li H, Liu Y, Huang H, Tang Y, Yang B, Huang C: Activation of $\beta 3$-adrenergic receptor inhibits ventricular arrhythmia in heart failure through calcium handling. Tohoku J Exp Med 2010;222:167-174.

20 Sui B, Li Z, Ao J: Metabolic remodeling and the failing heart. Zhongguo Xinxueguanbing Yan Jiu 2007;5:851853.

21 Tian Y, Zhu S, Wang J, Li Z, Song R, Nie L: Expression of $\beta 3$-adrenoceptor and peroxisome proliferatoractivated receptor $\alpha$ in human failing heart. Chin J Cardiol 2007;35:607-610.

-22 Morimoto A, Hasegawa H, Cheng HJ, Little WC, Cheng CP: Endogenous beta3-adrenoreceptor activation contributes to left ventricular and cardiomyocyte dysfunction in heart failure. Am J Physiol Heart Circ Physiol 2004;286:H2425-2433.

-23 Rozec B, Erfanian M, Laurent B, Trochu J, Chantal G: Nebivolol, a vasodilation selective beta1-blocker, is a beta3-adrenoceptor agonist in the nonfailing transplanted human heart. J Am Coll Cardiol 2009;53:15321538.

24 Mulder B, van Veldhuisen D, Crijns H, Bohm M, Cohen-Solal A, Babalis D, Roughton M, Flather M, Coats A, Van Gelder I: Effect of nebivolol on outcome in elderly patients with heart failure and atrial fibrillation: insights from SENIORS. Eur J Heart Fail 2012;14:1171-1178.

-25 Gill R, Cheung P, Yu X, Al Aklabi M, Nagendran J, Quinonez L, Li Y, Miller J, Ross D, Rebeyka I, Li J: $\beta 3$ adrenoceptor antagonist SR59230A attenuates the imbalance of systemic and myocardial oxygen transport induced by dopamine in newborn lambs. Clin Med Insights Cardiol 2012;6:45-51.

26 Thomas R, Holt B, Schwinn D, Liggett S: Long-term agonist exposure induces upregulation of $\beta 3$-adrenergic receptor expression via multiple cAMP response elements. Proc Natl Acad Sci USA 1992;89:4490-4494.

27 Zhao Q Zeng F, Liu J, He Y, Li B, Jiang Z, Wu T, Wang L: Upregulation of $\beta 3$-adrenergic receptor expression in the atrium of rats with chronic heart failure. J Cardiovasc Pharmacol Ther 2013;18:133-137.

-28 Sato M, Hutchinson DS, Evans BA, Summers RJ: The $\beta 3$-adrenoceptor agonist L755507 and antagonist L748337 activate different signalling pathways in CHO-K1 cells stably expressing the human $\beta 3$ adrenoceptor. Mol Pharmacol 2008;74:1417-1428.

29 Barth A, Merk S, Arnoldi E, Zwermann L, Kloos P, Gebauer M, Steinmeyer K, Bleich M, Kaab S, Hinterseer M, Kartmann H, Kreuzer E, Dugas M, Steinbeck G, Nabauer M: Reprogramming of the human atrial transcriptome in permanent atrial fibrillation: expression of a ventricular-like genomic signature. Circ Res 2005;96:1022-1029.

30 White CW, Holida MD, Marcus ML: Effects of acute atrial fibrillation on the vasodilator reserve of the canine myocardium. Cardiovasc Res 1986;20:683-689.

31 White CW, Kerber RE, Weiss HR, Marcus ML: The effects of atrial fibrillation on atrial pressure-volume and flow relationships. Cir Res 1982;151:205-215.

32 Stanley W, Recchia F, Lopaschuk G: Myocardial substrate metabolism in the normal and failing heart. Physiol Rev 2005;85:1093-1129.

-33 Lopaschuk G, Ussher J, Folmes C, Jaswal J, Staley W: Myocardial fatty acid metabolism in health and disease. Physiol Rev 2010;90:207-258.

-34 Burkart EM, Sambandam N, Han X, Gross RW, Courtois M, Gierasch CM, Shoghi K, Welch MJ, Kelly DP: Nuclear receptors PPAR $\beta / \delta$ and PPAR $\alpha$ direct distinct metabolic regulatory programs in the mouse heart. J Clin Invest 2007;117:3930-3939.

35 Duncan J, Bharadwaj K, Fong J, Mitra R, Sambandam N, Courtois M, Lavine K, Goldberg I, Kelly D: Rescue of cardiomyopathy in peroxisome proliferator-activated receptor-alpha transgenic mice by deletion of lipoprotein lipase identifies sources of cardiac lipids and peroxisome proliferator-activated receptor-alpha activators. Circulation 2010;121:426-435.

-36 Rowe G, Jiang A, Arany Z: PGC-1 coactivators in cardiac development and disease. Circ Res 2010;107:825838.

37 Madrazo J, Kelly D: The PPAR trio: regulators of myocardial energy metabolism in health and disease. J Mol Cell Cardiol 2008;44:968-975.

-38 Marionneau C, Aimond F, Brunet S, Niwa N, Finck B, Kelly D, Nerbonne JM: PPARalpha-mediated remodeling of repolarizing voltage-gated $\mathrm{K}^{+}(\mathrm{Kv})$ channels in a mouse model of metabolic cardiomyopathy. J Mol Cell Cardiol 2008;44:1002-1015.

-39 Ausma J, Coumans W, Duimel H, Vusse G, Allessie M, Borgers M: Atrial high energy phosphate content and mitochondrial enzyme activity during chronic atrial fibrillation. Cardiovasc Res 2000;47:786-796. 